\title{
ARBITRAJE, EXPROPIACIONES Y AMBIENTE. LA EXPERIENCIA DEL CAPÍTULO 11 DEL TRATADO DE LIBRE COMERCIO DE AMÉRICA DEL NORTE
}

\begin{abstract}
ARBITRAGEM, EXPROPRIACÕES E AMBIENTE. A EXPERIÊNCIA DO CAPÍTULO 11 DO TRATADO DE LIVRE COMÉRCIO NA AMÉRICA DO NORTE
\end{abstract}

\section{Luis Fernando Castillo Argañarás}

Resumen: El objetivo del presente artículo es analizar el régimen de expropiaciones en el Derecho Internacional de las Inversiones Extranjeras y su vinculación con el ambiente. Serán objeto de análisis los casos "Metalclad", "S.D.Myers", "Tecmed", surgidos en virtud del Capitulo 11 del TLCAN como paradigmáticos.

Resumo: O objetivo deste artigo é analisar o sistema de expropriação em Direito Internacional de Investimento Estrangeiro e sua relação com o ambiente. Serán casos analisados "Metalclad", "S.D.Myers", "Tecmed", decorrentes do Capítulo 11 TLCAN como paradigmaticos.

Palabras clave: Inversiones, Arbitraje, Ambiente, Expropiaciones Palavras-chave: Investimentos, Arbitragem, Ambiente, Expropriações

\section{INTRODUCCIÓN}

Existe un consenso global de que el desarrollo sustentable es un objetivo de toda la comunidad internacional y que la inversión extranjera directa es un componente clave para cualquier agenda de desarrollo ${ }^{1}$.

\footnotetext{
* Consejo Nacional de Investigaciones Cientificas y Técnicas (CONICET) de Argentina y Universidad Argentina de la Empresa (UADE). Doctor en Derecho (UBA) y Doctor en Ciencia Política (UB). Investigador del Consejo Nacional de Investigaciones Científicas y Técnicas (CONICET) de Argentina y de la Universidad Argentina de la Empresa (UADE), Profesor Titular Regular de Derecho Internacional Público en UADE y Profesor Titular Interino en la misma materia en la Universidad Nacional de Lomas de Zamora. Miembro del Comité Académico de la Maestría en Derecho Empresarial de UADE. Buenos Aires - Argentina. E-mail: lcastillo@uade.edu.ar

1 GEHRING, Markus and NEWCOMBE, Andrew. "An Introduction to Sustainable Development in World Investment Law". En: CORDONIER, Segger et al, Sustainable Development in World Investment Law. Kluwer Law International: The Netherlands, 2011. p. 3.
} 
No obstante, Sornarajah señala que "los grupos ambientalistas han considerado a las corporaciones multinacionales como las responsables de la contaminación causada sobre todo en los países en desarrollo, donde las normas ambientales son laxas"2. En ese sentido, la gestión de las cuestiones ambientales que realizan las empresas multinacionales es materia de controversia en numerosas ocasiones. Así, Petra Christmann sostiene que las corporaciones transnacionales explotan las diferentes regulaciones en ambiente que tienen los países Y ubican sus operaciones en distintos Estados con normas ambientales flojas y adaptan las actividades de sus subsidiarias a las políticas ambientales, tecnológicas y estándares del país receptor de la inversión ${ }^{3}$.

Muchas veces, los gobiernos adoptan medidas para proteger el ambiente, la salud, etc.; y de manera no discriminatoria pero tiene como consecuencia que causan un perjuicio a un inversionista extranjero. En ese sentido, Gehring y Newcombre consideran que "existe mucho por realizar para afianzar que el marco regulatorio actual para las inversiones extranjeras promueva el desarrollo sustentable"4.

Distintos Estados han comenzado a incorporar cláusulas o disposiciones sobre inversiones en convenios comerciales bilaterales o regionales. El más conocido es el Tratado de Libre Comercio de América del Norte (TLCAN o NAFTA) entre Canadá, EE.UU., y México de 1994 que en su Capítulo XI regula la protección de inversiones extranjeras.

Nicolas Schrijver señala que "en sus orígenes, el arbitraje en controversias sobre protección de inversiones extranjeras fue visto como un camino para promover el flujo de capitales a los países en desarrollo y así contribuir al desarrollo sustentable"

Desde los primeros casos planteados en el marco del TLCAN que involucraban medidas de protección ambiental han transcurrido muchos años. El incremento de los arbitrajes en materia de inversión contribuyó a clarificar en gran medida la regulación en este ámbito. En éste proceso de integración encontramos laudos que resolvieron sobre cuestiones ambientales relacionadas con inversiones. Ejemplo de ellos son: "Metalclad", "S.D.Myers", “Tecmed", entre otros. Se sigue en estas controversias el modelo "inversor - Estado" ante un tribunal arbitral para resolverla. El Articulo 1114 (I) del capítulo 11 de NAFTA establece: "Nada en este Capítulo se interpretará como impedimento para que una Parte adopte, mantenga, o haga cumplir cualquier medida, por lo demás

2 SORNARAJAH, M. The International Law on Foreign Investment. Third Edition, Cambridge University Press, 2010. p. 225.

3 CHRISTMANN, Petra. "Multinational Companies and the Natural Environment: Determinants of Global Environmental Policy Standarization" en Academy of Management Journal. 2004, vol 47, no 5, p. 747.

4 GEHRING, Markus et al. Op. Cit. p. 9.

5 SCHRIJVER, Nicolas. "Report of the International Law on Sustainable Development Committee". En: CHINKIN, Christine et al, (ed). Report of The Seventy Third Conference International Law Association, (Rio de Janeiro, 2008). London: s.n. 2008. p. 918. 
compatible con este capítulo, que considere apropiada para asegurar que las inversiones en su territorio se realiza de una manera sensible a las preocupaciones ambientales" ${ }^{6}$.

En ese sentido, surge el interrogante si esas medidas que adoptan los gobiernos para proteger el ambiente pueden considerarse como expropiatoria. Así, el objetivo del presente artículo será analizar el régimen de expropiaciones en el Derecho Internacional de las Inversiones Extranjeras y su vinculación con el ambiente. Fundamentalmente nos detendremos en la expropiación regulatoria de acuerdo a lo planteado y tomaremos como objeto de análisis los casos "Metalclad", "S.D.Myers", "Tecmed", surgidos en virtud del Capítulo 11 de NAFTA como más paradigmáticos. Metodológicamente iremos de lo general a lo particular. De la normativa general al caso particular como ser laudos arbitrales. De esa manera, llegaremos a las conclusiones.

\section{LA PROTECCIÓN DE LAS INVERSIONES EXTRANJERAS Y LA EXPROPIACIÓN}

August Reinisch considera que la expropiación en el sentido de una toma directa de la propiedad privada por el Estado, usualmente involucra una transferencia de los derechos de propiedad al Estado o a una tercera persona fue una de las cuestiones más importantes del Derecho Internacional Público durante el siglo $\mathrm{XX}^{7}$. En ese orden de ideas, las medidas de nacionalización de los comunistas y en Méjico en la década de 1920, seguidas de la socialización de la propiedad privada en los países de Europa del Este después de la II Guerra Mundial y las expropiaciones en los países en desarrollo en el curso del proceso de descolonización, así como las controversias sobre las concesiones de petróleo de 1960 y 1970, marcaron las más importantes olas de expropiaciones de la propiedad privada ${ }^{8}$. A ellas, le debemos sumar las nacionalizaciones que se realizaron en Irán a partir de 1979 que dieron lugar al establecimiento del Tribunal de Reclamos entre EE.UU e Irán. A partir de mediados de 1990 podemos ubicar una nueva ola de expropiaciones de las inversiones extranjeras que se tramitaron ante el Centro Internacional de Arreglo de Diferencias en Relativas a Inversiones (CIADI), en el marco del Banco Mundial.

Sohn y Baxter, en oportunidad de redactar la Convención sobre Responsabilidad Internacional de los Estados por Daños a los

\footnotetext{
6 "Nothing in this chapter shall be construed to prevent a Party from adopting, maintaining, or enforcing any measure, otherwise consistent with this chapter, that it considers appropriate to ensure that investment activity in its territory is undertaken in a manner sensitive to environmental concerns".

7 REINISCH, August. "Expropriation". En: MULCHLINSKI, Peter et al. (ed). The Oxford Handbook of International Investment Law. Oxford University Press, 2008. p. 408.

8 Ibídem.
} 
Extranjeros definieron la expropiación como "no es sólo una toma directa de propiedad, sino también cualquier interferencia irrazonable con el uso, goce o disposición de los bienes como para justificar una injerencia que el propietario del mismo no será capaz de usar, gozar o disponer de la propiedad".

Peter Malanczuk ${ }^{10}$ señala que los estándares internacionales mínimos de protección contienen dos reglas de derecho consuetudinario relativas a expropiación. La primera, la expropiación debe ser por interés público. Segundo, aún cuando la expropiación sea conforme a la regla antes mencionada, debe ir acompañada por el pago de una indemnización que debe ser por el valor total de la propiedad o como se expresa comúnmente, la compensación debe ser "pronta, adecuada y efectiva”. En ese sentido, Lowe ${ }^{11}$ estima que en el Derecho Internacional hay un considerable grado de consenso sobre el criterio acerca de los requisitos que debe reunir una expropiación legal. Así, la expropiación debe ser realizada: mediante ley, por causa de utilidad pública, no debe ser discriminatoria y se debe realizar el pago de una indemnización conforme el Derecho Internacional. Magdalena Ignacio, citada por Marisol Páez estima que "un concepto estricto de expropiación se refiere a la transferencia directa del título de propiedad, que comprende la nacionalización de toda la propiedad privada respecto de una producción; la nacionalización de una industria determinada para crear un monopolio del Estado; la expropiación en gran escala cuando hay toma de terrenos y su distribución en la población no propietaria; y las expropiaciones particulares de un terreno determinado" 12 .

El documento de la Comisión de Naciones Unidas sobre Comercio y Desarrollo (UNCTAD) 'titulado "Expropriation" puntualiza que "la crisis financiera internacional se ha hecho especialmente visible en la regulación de determinadas áreas que los Estados consideran de interés público. En ese sentido, se observa a los Estados interviniendo para rescatar algunos sectores de su economía y han tomado participaciones en empresas transnacionales"13. Así, surge la noción de expropiación indirecta.

9SOHN, Louis and BAXTER, R. "Responsibility of States for Injuries to the Economic Interest of Aliens II". Draft Convention on the International Responsibility of States for Injuries to Aliens, citados en EL ATTAR, Bassant et al. Expropriation Clauses in International Investment Agreements and the Appropriate Room for Host States to Enact Regulations: A Practical Guide for States and Investors. Geneve: The Graduate Institute of Geneva, Centre for Trade and Economic Integration, 2009. p. 5

10 MALANCZUK, Peter. Akehurst's Modern Introduction to International Law. Seven Revised Edition. London: Routledge, 2002. p. 235.

11 LOWE, Vaughan. "Changing Dimensions of International Investment Law". University of Oxford Faculty of Law Legal Studies Research Paper Series. 2007, nº 4, p. 53.

12 PÁEZ, Marisol. "La Expropiación Indirecta frente al CIADI: Consideraciones para la autorregulación de los actos administrativos de los Estados". Revista de Estudios Internacionales. 2006, vol 39, $\mathrm{n}^{\circ} 153$.

13 UNCTAD. Expropriation. New York- Geneve: United Nations, 2011. p. 15. 
Andrew Newcombe señala que "existen distintos tipos de expropiaciones y que ha sido denominada de distintas maneras, entre ellas expropiación directa, indirecta, medidas equivalentes a expropiación, expropiación encubierta u oculta, constructiva, de facto, regulatoria, virtual" 14 .

Además de la expropiación directa señalada anteriormente, en el Derecho Internacional se distingue la denominada expropiación indirecta. Conforme UNCTAD, este tipo de expropiación puede surgir cuando determinadas medidas gubernamentales pueden no involucrar una deprivación física de una propiedad pero tienen como resultado producir la pérdida efectiva de la gestión, uso o control, o una depreciación del valor del bien del inversionista extranjero ${ }^{15}$.

En el Tribunal formado entre Irán y Estados Unidos para entender las controversias surgidas entre ellos a partir de 1979 encontramos el caso Starret Housing. En esta oportunidad se señaló que "está reconocido en Derecho Internacional que las medidas tomadas por un Estado pueden interferir con los derechos de propiedad, hasta el punto de que estos derechos se vuelven tan vagos que debe considerarse que han sido expropiados, a pesar de que el Estado no tuvo la intención y el título legal de la propiedad sigue siendo formalmente del propietario original" 16 .

En el Informe denominado "Inversiones y Desarrollo Sustentable"17 del Instituto Internacional de Desarrollo Sustentable (con sede en Ginebra) se señala que "la expropiación indirecta en mucho más difícil"; y puntualiza que hasta la fecha se han observado varias formas o casos. En ese sentido encontramos ${ }^{18}$ :

- Una medida equivalente a la expropiación, es una medida que, aunque no se confisque directamente la propiedad, tiene las mismas repercusiones de privar en efecto al dueño de todos los beneficios de la propiedad (por ejemplo, el reemplazo de la Junta Directiva o el bloqueo del perímetro de un establecimiento para impedir la entrada o salida de productos,

- La expropiación progresiva, consistente en utilizar una serie de medidas para lograr una expropiación directa o indirecta. En este caso, ninguna medida por si sola equivaldría a una expropiación; pero la suma de las medidas podría considerarse como tal; y

- La expropiación reglamentaria, en cuyo caso, una medida se

14 NEWCOMBE, Andrew. "The Boundaries of Regulatory Expropriation under International Law”. 20 ICSID Review. 2005, nº 1, p. 20.

15 UNCTAD. Op. Cit. p. 2

16 HEISKANEN, Veijo. “The Contribution of the Iran-United States Claims Tribunal to The Development of the Doctrine of Indirect Expropriation”. En: International Law Forum. 2003, vol $5, \mathrm{n}^{\circ} 3$. p. 181.

17 COSBEY, Aaron, et al. Inversiones y Desarrollo Sustentable. Canadá: International Institute for Sustainable Development, 2004. p. 14.

18 Ibídem. 
adopta con finalidades reglamentarias tradicionales pero tiene tales repercusiones sobre un inversionista extranjero que se considera una expropiación (un subconjunto de medidas equivalentes a la expropiación).

\section{EL TRATADO DE LIBRE COMERCIO DE AMÉRICA DEL NORTE Y EL AMBIENTE}

El "Tratado de Libre Comercio de América del Norte" conocido también como TLCAN o por su sigla en inglés NAFTA es el primer acuerdo de integración regional de alcance general que involucra a países con niveles de desarrollo dispares" ${ }^{\prime 1}$. Fue firmado por los Presidentes de Estados Unidos y México y por el Primer Ministro de Canadá, el 17 de diciembre de 1992.

El TLCAN significó el establecimiento de una zona de libre comercio "en el territorio de lo que se conoce geográficamente como América del Norte que en aquel momento poseía el mayor número de habitantes en el mundo" 20 , y el Capítulo 11 de NAFTA "logró por primera vez que un tratado de libre comercio introdujera un capítulo específico que regulara y legislara de manera supranacional la inversión extranjera" 21 .

La particularidad de este acuerdo es que incluye tres mecanismos distintos de solución de controversias. El primero relativo a la interpretación, aplicación y violación al Acuerdo (Capítulo 20). El segundo sobre cuotas anti dumping y compensatorias. El tercero establece el mecanismo de solución de controversias entre inversores extranjeros y el Estado receptor de la inversión (Capítulo 11).

David R. Haig, citado por Jones ${ }^{22}$, considera que el Capítulo 11 del NAFTA es, en esencia, un acuerdo trilateral de inversiones injertado en un acuerdo que está relacionado directamente con la liberalización y equidad en el comercio de bienes y servicios. Al igual que todo tratado moderno en su naturaleza contiene disposiciones para la solución de controversias y como tratado de inversiones sigue simplemente el ya establecido modelo para la solución de controversias entre un inversor $\mathrm{y}$ un Estado $^{23}$. El mismo autor agrega que el objetivo fundamental del

19 MONGE-NARANJO, Alexander. The Impact of NAFTA on Foreign Direct Investment flows in Mexico and the Excluded Countries [en línea]. s.l: Department of Economics. Northwestern University, 2002 [consulta 9/12/2014]. Disponible en: <http://web.worldbank.org/archive/ website00894A/WEB/PDF/MONGE_NA.PDF>.

20 GUTIERREZ - HACES, Teresa. "La Inversión Extranjera Directa en el TLCAN". Economíaunam [en línea]. 2004, vol 1, no 3 [consulta 5/12/2014]. Disponible en: <http://www. revistas.unam.mx/index.php/ecu/article/view/2814>.

21 Ibídem.

22 JONES, Ray C. "NAFTA Chapter 11 Investor - to State Dispute Resolution: A Shield to be Embraced or a Sword to be Feared?". Brigham Young University Law Review. 2002, p. 531.

23 Ibídem 
Capítulo 11 de solución de controversias fue crear negocios entre los inversores y los Estados receptores. En ese sentido, los inversores aceptan realizar inversiones en otro Estado convencidos que se les asegura el disfrute de los estándares básicos de justicia y equidad establecidos en la Sección A del Capítulo 11. Esta protección es esencial para los inversores extranjeros que están sometidos a la autoridad legislativa del Estado receptor quedando vulnerables a sus facultades regulatorias de este Estado ${ }^{24}$.

Oscar Cruz Barney señala que la sección B del Capítulo 11 de NAFTA "responde a la búsqueda por parte de los inversionistas de las mejores condiciones de seguridad, certeza jurídica y rendimientos (...) de ahí la creación de un mecanismo arbitral especial para prevenir y resolver las controversias que pudieren surgir cuando un inversionista considere que se le está vulnerando algún derecho"25. El sistema implementado para solucionar las controversias es el Arbitraje; pero primero debe recurrirse a las consultas y negociación.

El Capítulo 11 establece una serie de obligaciones sustantivas a los Estados hacia los inversores extranjeros. Ellas se encuentran desde el Art. 1102 al 1114, y serán considerados a continuación.

La primera obligación se refiere al principio de trato nacional. En ese sentido, "cada una de las Partes otorgará a los inversionistas de otra Parte un trato no menos favorable que el que otorgue, en circunstancias similares, a sus propios inversionistas en lo referente al establecimiento, adquisición, expansión, administración, conducción, operación, venta u otra disposición de las inversiones" y "cada una de las Partes otorgará a las inversiones de inversionistas de otra Parte, trato no menos favorable que el que otorga, en circunstancias similares, a las inversiones de sus propios inversionistas en el establecimiento, adquisición, expansión, administración, conducción, operación, venta u otra disposición de las inversiones" (Art. 1102 Ap. 1 y 2).

La segunda obligación está relacionada con el principio de la nación más favorecida. Así, "cada una de las Partes otorgará a los inversionistas de otra Parte trato no menos favorable que el que otorgue, en circunstancias similares, a los inversionistas de cualquier otra Parte o de un país que no sea Parte, en lo referente al establecimiento, adquisición, expansión, administración, conducción, operación, venta u otra disposición de inversiones. (Art. 1103, Ap. 1) y "cada una de las Partes otorgará a las inversiones de inversionistas de otra Parte un trato no menos favorable que el que otorgue, en circunstancias similares, a las inversiones de inversionistas de cualquier otra Parte o de un país que no sea Parte, en lo referente al establecimiento, adquisición, expansión,

24 Ibídem

25 CRUZ BARNEY, Oscar. "Protección al Medio Ambiente y Solución de Controversias en Materia de Inversiones en el TLCAN". Revista de Derecho Privado. 2004, vol 3, n 7, p. 49. 
administración, conducción, operación, venta u otra disposición de inversiones". (Art. 1103 Ap. 2).

En el Art. 1105 se establece la obligación de un mínimo nivel de trato. Así, "Cada una de las Partes otorgará a las inversiones de los inversionistas de otra Parte, trato acorde con el derecho internacional, incluido trato justo y equitativo, así como protección y seguridad plena."

El Art. 1106 prohíbe a las Partes del Tratado imponer ciertos requisitos de desempeño a los inversores extranjeros. No se les podrá imponer que deben exportar un determinado nivel o porcentaje de bienes o servicios; o alcanzar un determinado grado o porcentaje de contenido nacional, etc.

El Art. 1109 establece la obligación que el Estado receptor de la inversión "permitirá que todas las transferencias relacionadas con la inversión de un inversionista de otra de las Partes en territorio de la Parte, se hagan libremente y sin demora". Estas transferencias incluyen ganancias, dividendos, intereses, ganancias de capital, pagos por regalías, gastos por administración, asistencia técnica y otros cargos, ganancias en especie y otros montos derivados de la inversión; hasta productos derivados de la venta o liquidación, total o parcial, de la inversión e incluidos los pagos por préstamos y las compensaciones por violaciones al Tratado.

El Art. 1110 establece una serie de disposiciones relativas a expropiaciones. En ese orden de ideas, ninguna de las Partes podrá nacionalizar ni expropiar, directa o indirectamente, una inversión de un inversionista de otra Parte en su territorio, ni adoptar ninguna medida equivalente a la expropiación o nacionalización de esa inversión (expropiación), salvo que sea: a) por causa de utilidad pública; $b$ ) sobre base no discriminatoria; $c$ ) siguiendo el debido proceso legal; $d$ ) mediante el pago de una indemnización. Esta compensación debe ser pronta, adecuada y efectiva. Debe ser realizada al valor justo de mercado que tenga la inversión expropiada inmediatamente antes de que la medida expropiatoria se haya llevado a cabo (fecha de expropiación), y no reflejará ningún cambio en el valor debido a que la intención de expropiar se conoció con antelación a la fecha de expropiación. Los criterios de valuación incluirán el valor corriente, el valor del activo (incluyendo el valor fiscal declarado de bienes tangibles), así como otros criterios que resulten apropiados para determinar el valor justo de mercado. En caso de que la indemnización sea pagada en la moneda de un país miembro del Grupo de los Siete, la indemnización incluirá intereses a una tasa comercial razonable para la moneda en que dicho pago se realice, a partir de la fecha de la expropiación hasta la fecha de pago. Aunque, si una Parte elige pagar en una moneda distinta a la del Grupo de los Siete, la cantidad pagada no será inferior a la equivalente que por indemnización se hubiera pagado en la divisa de alguno de los 
países miembros del Grupo de los Siete en la fecha de expropiación y esta divisa se hubiese convertido a la cotización de mercado vigente en la fecha de expropiación, más los intereses que hubiese generado a una tasa comercial razonable para dicha divisa hasta la fecha del pago (Art. 1110).

El Capítulo también establece una regulación sobre las medidas ambientales. En ese sentido establece que las Partes del Tratado tienen el derecho de adoptar y aplicar medidas ambientales conforme a este capítulo. Las Partes también reconocen que es inadecuado alentar la inversión mediante la flexibilización de cuestiones relacionadas con la salud (relaxing domestic health), seguridad o medio ambiente. En consecuencia, las Partes no deben renunciar o derogar dichas medidas ambientales para atraer inversiones (Art. 1114).

\section{ARBITRAJES SOBRE AMBIENTE EN EL MARCO DEL CAPÍTULO 11 DE NAFTA}

Cosbey, refiriéndose a la modalidad de la expropiación reglamentaria, señala que "se aplicala denominada doctrina delos EE.UU. que según algunos, una reglamentación puede equivaler a una forma de expropiación indirecta si tiene repercusiones negativas significativas en el valor económico de una inversión" 26 . Este autor considera que con el avenimiento del Capítulo 11 del TLCAN, el debate sobre este concepto ampliado de expropiación paso de los sistemas judiciales y políticos de los EE.UU a la palestra de los arbitrajes internacionales, impulsado por los inversionistas extranjeros que ponen a prueba las clausulas"27. En ese sentido, analizaremos los casos relacionados con la expropiación reglamentaria. Focalizaremos en los arbitrajes de Metalclad, S.D.Myers, Inc. y Tecmed porque son paradigmáticos en este ámbito.

\subsection{Caso METALCLAD vs. México ${ }^{28}$}

Fue uno de los primeros casos en que se planteó la expropiación reglamentaria. Está relacionado con la empresa Metalclad Corp. de EE. UU. a la que se le había negado la posibilidad de instalar una planta para procesamiento de desechos peligrosos en La Pedrera, valle localizado en Guadalcázar, San Luis de Potosí (México).

El 26 de octubre de 1994 se terminó abruptamente la construcción de la planta, cuando el Municipio ordenó el cese de toda actividad debido a la falta de permiso municipal de construcción. De mayo de

26 COSBEY, Aaron, et al. Op. Cit. p. 14

27 Ibídem.

28 Seguimos el relato conforme el laudo del Centro Internacional de Arreglo de Diferencias Relativas a Inversiones, Mecanismo Complementario, Caso N ARB (AF)/97/1: Metalclad Corporation y Estados Unidos Mexicanos. Fecha de envío a las Partes: 30 de agosto de 2000. 
1996 a diciembre de 1996, Metalclad y el Estado de San Luis de Potosí (SLP) intentaron resolver los asuntos relativos a la operación del confinamiento. Estos esfuerzos fracasaron y, el 2 de enero de 1997, Metalclad inició el procedimiento de arbitraje en contra del Gobierno de México al amparo del Capítulo 11 del NAFTA.

El 23 de septiembre de 1997, el Gobernador de SLP, tres días antes de que terminara su período de gobierno, emitió un Decreto Ecológico declarando un Área Natural para la protección de un cactus único. El Área Natural abarcaba el área del confinamiento. Metalclad se basa en parte en este Decreto Ecológico como un elemento adicional a su reclamación, sosteniendo que el Decreto efectiva y permanentemente precluye la operación del confinamiento.

El Tribunal determinó que la expropiación en NAFTA “incluye no sólo la confiscación de la propiedad de manera abierta, deliberada y con conocimiento de causa, tal como una confiscación directa o una transferencia formal u obligatoria de títulos en favor del Estado receptor, sino también una interferencia disimulada o incidental del uso de la propiedad que tenga el efecto de privar, totalmente o en parte significativa, al propietario del uso o del beneficio económico que razonablemente se esperaría de la propiedad, aunque no necesariamente en beneficio obvio del Estado" 29 y que "Tribunal arbitral en este caso laudo que "no necesitaba determinar ni considerar la motivación ni las intenciones de la adopción del Decreto Ecológico" 30 .

Justin Marlles señala que este laudo es el más pro-inversor que cualquier otra interpretación del Art. 1110 en el marco del Capítulo 11 de NAFTA ${ }^{31}$.

\subsection{Caso S.D.Myers, Inc. vs. Canadá ${ }^{32}$}

S.D. Myers Inc. es una empresa de nacionalidad de EE.UU. cuyo objeto es el tratamiento de desechos tóxicos. Así, importaba hacia Ohio desde Canadá un desecho llamado Polychlorinated Biphenyls (en inglés) ó Bifenilos Policlorados (en castellano) - PCB. Los PCB se utilizan principalmente en equipos eléctricos y en menor medida en otros productos. Estos se biodegradan lentamente, permanecen en el ambiente por un largo tiempo; y deben ser eliminados a través de cualquiera de los procesos de destrucción térmica a altas temperaturas

29 Ibídem. para. 103

30 Ibidem, para. 111

31 MARLLES, Justin. "Public Purpose, Private Losses: Regulatory Expropriation and Environmental Regulations In International Investment Law”. Journal of Transnational Law \& Policy. 2007, vol 16, n² 2, p. 280.

32 Seguimos el relato conforme el laudo en el marco de NAFTA dictado conforme las Reglas de UNCITRAL de Arbitraje en S.D. Myers (Claimant) and Goverment of Canada (Respondent). Partial Award, November 13, 2000. 
o por procesamiento químico. Los vertederos se utilizan también como un medio de eliminación, pero este método sólo contiene el material de una manera relativamente segura y no resultará en la eliminación de la sustancia desde el medio ambiente. La técnica más utilizada para destruir a esta sustancia es la incineración a alta temperatura, típicamente a temperaturas de aproximadamente 1200 grados Centígrados ${ }^{33}$.

En marzo de 1989, varios Estados, entre ellos Canadá firmaron el Convenio de Basilea. Esta Convención trata sobre el tráfico internacional de PCB y otros desechos peligrosos. Ha sido adoptada bajo los auspicios del Programa de las Naciones Unidas para el Medio Ambiente. Aunque los EE.UU. firmaron el Convenio de Basilea no lo había ratificado en el momento de los hechos que se examinan en el arbitraje ${ }^{34}$.

Los Estados Partes en el Convenio de Basilea aceptan la obligación de garantizar que los residuos peligrosos sean manejados de manera ambientalmente racional. El Convenio de Basilea establece normas y procedimientos que rigen el movimiento transfronterizo de desechos peligrosos y su eliminación. Entre otras cosas, se prohíbe la exportación e importación de desechos peligrosos desde y hacia los Estados que no son parte en el Convenio de Basilea (artículo 4 (5)), a menos que tal movimiento está sujeto a los acuerdos bilaterales, multilaterales o regionales cuyas disposiciones son no menos estrictas que las del Convenio de Basilea (artículo 11) ${ }^{35}$.

En 1993, Myers se constituyó bajo la Business Corporations Act de Canada $^{36}$. En noviembre de 1995, Canadá prohíbe la exportación de manera temporal de PCB. En ese lapso revisaba los tratados internacionales sobre manejo de sustancias tóxicas ${ }^{37}$.

En octubre de 1998, S.D. Myers inició un procedimiento arbitral contra Canadá por U\$S 20 millones, argumentando expropiación, violación de cláusula de nación más favorecida, de trato no discriminatorio, de trato justo y equitativo, además de mala fe y denegación de justicia”.

En este caso, el tribunal laudó que "la conducta reglamentaria de las autoridades públicas tiene pocas probabilidades de ser objeto de una demanda legítima al amparo del Art. 1110 del TLCAN, aunque el tribunal no descarta esa posibilidad. Las expropiaciones tienden a llevar aparejada la privación delos derechos de propiedad; las reglamentaciones son una interferencia menor" 38 .

Sintetizando, en este caso, el Tribunal distinguió las regulaciones de la expropiación, fundamentalmente sobre la base del grado de

33 Ibídem. paras. 88 a 96

34 Ibídem. para. 105

35 Ibídem. para. 106

36 Ibídem. para. 111

37 Ibídem. para. 123 a 128

38 Ibídem. para. 282 
interferencia con los derechos de propiedad.

\subsection{Caso TECMED vs. México ${ }^{39}$}

La controversia se relaciona con una inversión en terrenos, construcciones y otros activos a raíz de una subasta en licitación pública convocada por Promotora Inmobiliaria del Ayuntamiento de Hermosillo («Promotora»), un Organismo Público Descentralizado Municipal de dicho ayuntamiento ubicado en el Estado de Sonora, México. El objeto de la subasta fue la venta de un inmueble, construcciones e instalaciones y otros bienes relativos al confinamiento controlado de desechos industriales peligrosos «Cytrar». Como consecuencia de tal subasta, Tecmed resultó adjudicataria de dichos bienes, según decisión adoptada por el Consejo de Administración de Promotora del 16 de febrero de 1996. Ulteriormente, la titularidad de los derechos y obligaciones de Tecmed bajo la subasta y en relación con los bienes del confinamiento quedó en cabeza de Cytrar, sociedad esta última constituída por Tecmed a tales efectos y para que operara dicho confinamiento.

El confinamiento fue construído en 1988 sobre un terreno adquirido por el Gobierno del Estado de Sonora que se encuentra ubicado en la localidad de Las Víboras, dentro de la jurisdicción del Ayuntamiento de Hermosillo, Estado de Sonora, México. A partir del 7 de diciembre de 1988, el confinamiento contó con una licencia para funcionar de una duración de cinco años prorrogable.

El 25 de noviembre de 1998, fue negada la solicitud de renovación de la autorización de funcionamiento del confinamiento que vencía el 19 de noviembre de 1998. En consecuencia, se planteó el reclamo arbitral ${ }^{40}$.

El Tribunal laudó que "las medidas adoptadas por un Estado, sean reglamentarias o no, constituyen una expropiación de facto indirecta si son irreversibles y permanentes y si los activos o derechos a los que se aplica la medida han sido afectados de tal manera que ha desaparecido toda forma de explotación. La intención del gobierno es menos importante que los efectos de las medidas para el dueño de los activos o los beneficios de los activos afectados por las medidas y la forma de la medida de privación es menos importante que sus efectos reales" ${ }^{31}$.

Coincidimos con la opinión de Cosbey que "lo más importante aquí es que el tribunal, en realidad, estableció una jerarquía de intereses por proteger; si la intención del gobierno es menos importante que los efectos sobre el inversionista, luego el razonamiento debe extenderse a una determinación de que el interés público es un factor menos

39 Seguimos el relato conforme el laudo del Centro Internacional de Arreglo de Diferencias Relativas a Inversiones, Caso $\mathrm{N}^{\circ} \mathrm{ARB}(\mathrm{AF}) / 00 / 2$ : Técnicas Medioambientales Tecmed S.A. Vs. Estados Unidos Mexicanos. Fecha de envío a las Partes: 29 de mayo de 2003.

40 Ibídem. paras 35 a 38 .

41 Ibídem. para 116. 
importante que los intereses de los inversionistas extranjeros privados" ${ }^{42}$.

\section{A MODO DE CONCLUSIÓN}

En numerosos tratados bilaterales de inversiones, o disposiciones sobre inversiones en acuerdos comerciales multilaterales, regionales o bilaterales, no encontramos disposiciones sobre la cuestión ambiental. No obstante, existe una nueva tendencia a incorporar normas especiales sobre ambiente en los acuerdos que regulan las inversiones extranjeras como en el Capítulo 11 de NAFTA. Este último acuerdo, contiene obligaciones sustantivas como ser: principio de trato nacional, cláusula de la nación más favorecida y mínimo nivel de trato, entre otras.

No puede estar ausente la regulación de la expropiación en un acuerdo sobre inversiones extranjeras. Ninguna de las Partes podrá nacionalizar ni expropiar, directa o indirectamente, una inversión de un inversionista de otra Parte en su territorio, ni adoptar ninguna medida equivalente a la expropiación o nacionalización de esa inversión. Solo procede mediando: a) declaración de utilidad pública, b) base no discriminatoria, $c$ ) se haya seguido el debido proceso legal y $d$ ) se pague una indemnización que debe ser pronta, adecuada y efectiva.

Existen distintos tipos de expropiaciones y han recibido distintas denominaciones, entre ellas expropiación directa, indirecta, medidas equivalentes a expropiación, expropiación encubierta $\mathrm{u}$ oculta, constructiva, de facto, regulatoria, virtual.

El TLCAN establece que las Partes reconocen que es inadecuado alentar la inversión mediante las normas que permitan flexibilizar las cuestiones relativas a la salud (relaxing domestic health), seguridad o medio ambiente. En consecuencia, las Partes no deben renunciar o derogar dichas medidas ambientales para atraer inversiones (Art. 1114). En ese sentido, tuvo importancia la expropiación regulatoria. Entendemos a esta última como una medida que se adopta con finalidades reglamentarias tradicionales pero con ciertas repercusiones sobre un inversionista extranjero que se considera una expropiación.

El Arbitraje es el mecanismo implementado para solucionar las controversias. En ese orden de ideas, consideramos tres casos paradigmáticos de expropiación reglamentaria vinculados al ambiente. En el caso METALCLAD, el laudo fue pro inversor. Brindó una amplia protección al inversionista; ya que consideró que "no necesita determinar ni considerar la motivación ni las intenciones de la adopción del Decreto Ecológico". Para el Tribunal fue suficiente la existencia de la interferencia sustancial. La perspectiva varió en el caso S.D. MYERS; ya que el Tribunal estimó que "la conducta reglamentaria de las autoridades públicas tiene pocas probabilidades de ser objeto de una demanda legítima al amparo

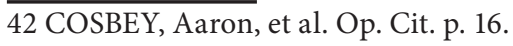


del Art. 1110 del TLCAN" y finalmente en el caso TECMED, el tribunal estableció una jerarquía de intereses por proteger; si la intención del gobierno es menos importante que los efectos sobre el inversionista.

A lo largo de estas líneas, llegamos a la conclusión que es necesario garantizar una adecuada protección al ambiente y establecer de manera clara los límites de un gobierno para regular la inversión extranjera y que no sea considerada expropiatoria.

\section{REFERENCIAS BIBLIOGRAFICAS}

CHRISTMANN, Petra. "Multinational Companies and the Natural Environment: Determinants of Global Environmental Policy Standarization" en Academy of Management Journal. 2004, vol 47, $\mathrm{n}^{\circ} 5$. CORDONIER SEGGER, Marie-Claire et al. Sustainable Development in World Investment Law. The Netherlands. Wolters Kluwer, 2011.

COSBEY, Aaron, et al. Inversiones y Desarrollo Sustentable. Canadá: International Institute for Sustainable Development, 2004.

CRUZ BARNEY, Oscar. "Protección al Medio Ambiente y Solución de Controversias en Materia de Inversiones en el TLCAN". Revista de Derecho Privado. 2004, vol 3, no 7, p. 49.

EL ATTAR, Bassant et al. Expropriation Clauses in International Investment Agreements and the Appropriate Room for Host States to Enact Regulations: A Practical Guide for States and Investors. Geneve: The Graduate Institute of Geneva, Centre for Trade and Economic Integration , 2009.

GEHRING, Markus and NEWCOMBE, Andrew. "An Introduction to Sustainable Development in World Investment Law". En: CORDONIER Segger et al, Sustainable Development in World Investment Law. KluwerLaw International: TheNetherlands, 2011.

GUTIERREZ-HACES, Teresa. "La Inversión Extranjera Directa en el TLCAN". Economíaunam [en línea]. 2004, vol 1, no 3 [consulta 5/12/2014]. Disponible en: <http://www.revistas.unam.mx/index.php/ ecu/article/view/2814>

HEISKANEN, Veijo. “The Contribution of the Iran-United States Claims Tribunal to The Development of the Doctrine of Indirect Expropriation". International Law Forum. 2003, vol 5, n 3. p. 181.

JONES, Ray C. "NAFTA Chapter 11 Investor - to State Dispute Resolution: A Shield to be Embraced or a Sword to be Feared?". Brigham Young University Law Review. 2002, p. 531.

LOWE, Vaughan. "Changing Dimensions of International Investment Law". University of Oxford Faculty of Law Legal Studies Research Paper Series. 2007, no 4, p. 53.

MALANCZUK, Peter. Akehurst's Modern Introduction to International Law. Seven Revised Edition. London: Routledge, 2002. p. 235. MARLLES, Justin. "Public Purpose, Private Losses: Regulatory 
Expropriation and Environmental Regulations In International Investment Law". Journal of Transnational Law \& Policy. 2007, vol 16, no 2, p. 280.

MONGE-NARANJO, Alexander. The Impact of NAFTA on Foreign Direct Investment flows in Mexico and the Excluded Countries [en línea]. s.l: Department of Economics. Northwestern University, 2002 [consulta 9/12/2014]. Disponible en: <http://web.worldbank.org/archive/ website00894A/WEB/PDF/MONGE_NA.PDF $>$.

MULCHLINSKI, Peter et al. (ed). The Oxford Handbook of International Investment Law. Oxford University Press, 2008.

NEWCOMBE, Andrew. "The Boundaries of Regulatory Expropriation under International Law”. 20 ICSID Review. 2005, nº 1, p. 20.

OCDE. "Indirect Expropriation and the right to Regulatein International Law". En: OCDE, Working Papers on International Investment $N^{\circ} 4$. OECD Publishing, 2004.

PÁEZ, Marisol. "La Expropiación Indirecta frente al CIADI: Consideraciones para la autorregulación de los actos administrativos de los Estados". Revista de Estudios Internacionales. 2006, vol 39, nº 153.

REY VALLEJO, Pablo. "El Arbitraje de Inversiones y los Retos de la Globalización”. Revista de Derecho Privado. 2007, n 38.

SCHRIJVER, Nicolas. "Report of the International Law on Sustainable Development Committee". En: CHINKIN, Christine et al, (ed). Report of The Seventy Third Conference International Law Association, (Rio de Janeiro, 2008). London: s.n. 2008.

SORNARAJAH, M. The International Law on Foreign Investment. 3th ed. Cambridge: Cambridge University Press, 2010.

SORNARAJAH, M. The International Law on Foreign Investment. Third Edition, Cambridge University Press, 2010.

UNCTAD. Expropriation. New York- Geneve: United Nations, 2011. p. 15.

UNCTAD. Taking of Property. New York - Geneve: United Nations, 2000. 